\title{
Enhancing financial protection under China's social health insurance to achieve universal health coverage
}

\section{Hai Fang and colleagues highlight the need for better financial protection for poor people}

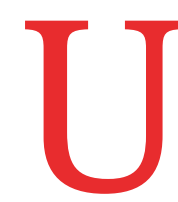

niversal health coverage means that all individuals and communities should get the quality health services they need without incurring financial hardship. ${ }^{1}$ It has three dimensions: population coverage, covering all individuals and communities; service coverage, reflecting the comprehensiveness of the services that are covered; and cost coverage, the extent of protection against the direct costs of care. ${ }^{2}$

The UN sustainable development goals in 2016 committed countries to achieve universal health coverage by 2030 with a focus on essential health services and financial protection. ${ }^{3}$ A recent report by the World Health Organization and the World Bank showed that China had a fairly high score for coverage of essential health services on 16 health indicators but a low score for financial protection to reduce the risk of illness induced poverty. ${ }^{4}$

China started comprehensive health system reforms in 2009, and in another article in this series Meng and colleagues provide a detailed review of these. ${ }^{5}$ An important goal of China's health system reforms was to achieve universal health coverage through building a social health insurance system. We examine China's progress in enhancing financial protection of social health insurance and identify the

\section{KEY MESSAGES}

- China has achieved near-universal health insurance coverage, which has greatly increased access to and use of health services

- Financial protection for poor populations needs to be enhanced as they are more likely to have catastrophic health expenses

- Increased spending on health will not improve financial protection without further measures to increase health system efficiency, strengthen primary care, and reform provider payment systems main gaps that need to be filled to fully achieve universal health coverage.

\section{What was proposed in the $\mathbf{2 0 0 9}$ reform?}

The 2009 health system reforms proposed a universal health insurance system that consisted of three main social health schemes: urban employee basic medical insurance (UEBMI), urban resident basic medical insurance (URBMI), and rural new cooperative medical scheme (RNCMS), with other supplementary insurance and private insurance (table 1). ${ }^{7}$ The 2009 reforms aimed to cover all the Chinese population with one of the three basic schemes to give them greater financial protection. In 2016, the urban resident and rural schemes merged to form the urban rural resident basic medical insurance (URRBMI) to improve administrative efficiency. ${ }^{8}$

To give added protection to patients with critical illnesses, catastrophic medical insurance (also called critical illness insurance or $\mathrm{Da}$ Bing $\mathrm{Yi} \mathrm{Bao}$ ) was initially launched in 2012 and implemented nationally in 2015. It covers patients with critical illnesses whose out-of-pocket expenses are more than the average disposable income per capita in the local area, providing extra reimbursement and removing the benefit ceiling.

The medical aid programme (also called medical financial assistance or Yi Liao Jiu Zhu), which was launched in 2003 in rural areas and expanded to urban areas in 2005, provides a further safety net. It was designed to provide medical aid to the poorest people by paying their medical insurance premiums and reducing out-of-pocket expenses after receiving reimbursement from the basic social health insurance schemes and catastrophic medical insurance. Funding for medical aid is mainly from governments, welfare lotteries, and social donations. ${ }^{9}$

China also invested a substantial amount of public funds in health services. Government healthcare budgets financed building and renovating government primary care facilities, subsidies to replace provider revenues generated from drug dispensing, purchase of medical equipment for public hospitals, expansion of public health services, and training and continuing medical education. These investments into the public health system increased the number of health workers from 3.48/1000 population in 2003 to $6.47 / 1000$ in 2017 and the number of hospital beds from 2.34/1000 in 2003 to $5.72 / 1000$ in 2017 , among other effects. ${ }^{610}$ Government investments also helped keep the prices of healthcare services low.

\section{What has been achieved in financial protection since 2009?}

The expansion of health insurance improved access to and use of healthcare. In 2011, China achieved near-universal health insurance coverage, with more than $95 \%$ of the Chinese population covered by health insurance. ${ }^{11}$ The percentage of people who were reported a "need" for hospital admission but did not receive inpatient care decreased from $29.6 \%$ in 2003 to $25.1 \%$ in 2008 , and to $17.1 \%$ in $2013 .^{12}$ The average number of outpatient visits per capita increased from 1.7 in 2003 to 5.9 in 2017 , and the annual inpatient hospital admission rate (the number of admissions in the country divided by the total population) also increased from 3.6\% in 2003 to $17.6 \%$ in $2017 .{ }^{61314}$ Use of outpatient services in China was comparable with the global average, but admission rates were much higher. ${ }^{15}$

\section{Drop in out-of-pocket health expenses}

The expansion of health insurance coverage in China reduced the share of outof-pocket heath expenses in total health expenditures. In China, national health expenditures are categorised according to three health funding sources: government budgets (including health service investments and social health insurance subsidies), social expenditures (including individual and employer contributions to social health insurance, private health insurance contributions, and social donations), and out-of-pocket spending. ${ }^{6}$ High 


\begin{tabular}{|c|c|c|c|c|c|}
\hline Scheme & Launch year & Covered population & Coverage rate in 2015 & Pooling level & Premium contribution \\
\hline Urban employee basic medical insurance & 1998 & Urban employees and retired & $95 \%$ & City & Employee and employer \\
\hline Urban resident basic medical insurance* & 2007 & $\begin{array}{l}\text { Urban non-employed and self } \\
\text { employed }\end{array}$ & $95 \%$ & City & Individual with government subsidies \\
\hline Rural new cooperative medical scheme* & 2002 & Rural people & $99 \%$ & County & Individual with government subsidies \\
\hline
\end{tabular}

out-of-pocket health expenses often mean low financial protection.

Figure 1 shows that the share of outof-pocket health expenses in total health expenditures fell from $56 \%$ in 2003 to $29 \%$ in 2017 . It is projected to decrease to $25 \%$ by $2030 .^{16}$

\section{Enhanced financial protection for poor populations}

Catastrophic medical insurance and medical aid were effective in supplementing the basic social health insurance schemes and provided extra financial protection to a range of vulnerable groups, including people who are poor; chronically ill or disabled, disadvantaged by geographical factors, very young, or frail and old. By 2017, more than a billion people in China were covered by catastrophic medical insurance and 11 million people received extra benefits of more than $¥ 30 \mathrm{bn}$ (£3.4bn; €3.9bn; $\$ 4.3 \mathrm{bn}) .{ }^{17}$ The insurance reduced the average proportion of out-of-pocket expenses after reimbursement from basic social health schemes by about $10 \%{ }^{18}$ In 2017 , through medical aid, 56.2 million people ( $4 \%$ of the population) received subsidies to pay for their social health insurance premiums, and 35.2 million people $(2.5 \%)$ received on average $¥ 757$ (about $12 \%$ of average inpatient spending per admission in 2017) to cover out-of-pocket expenses. ${ }^{6}$

\section{What should be done to further progress?} Reduce out-of-pocket health expenses Although the proportion of health expenditures accounted for by out-of-pocket payments is decreasing, the payments

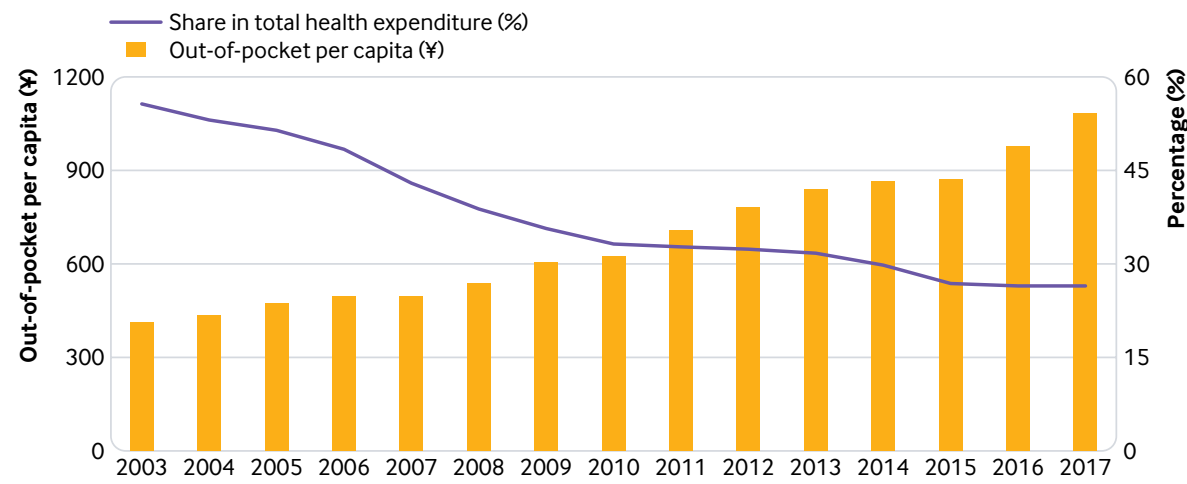

Year

remain fairly high. Figure 1 shows that the amount of out-of-pocket health expenses per capita continued to increase. In 2013, out-of-pocket expenditure per inpatient admission represented $33 \%$ and $30 \%$ of annual disposable for the population covered by RNCMS and URBMI, respectively. ${ }^{12}$

High out-of-pocket spending is one of the main reasons for catastrophic health expenses and low financial protection in China. ${ }^{1419}$ Catastrophic health expense is often defined to occur when a household's total out-of-pocket health payments is $40 \%$ or more of the household's capacity to pay (ie, net income after essential spending). ${ }^{20}$ According to this definition, the incidence of catastrophic health expenses in the total population was $12.2 \%$ in $2003,14 \%$ in 2008 , and $12.9 \%$ in $2011 .{ }^{14}$ Though no national official statistics for catastrophic health expenses were released after 2011, studies using regional data suggest that the rate of catastrophic health expenses has not declined since 2011 (table 2).

To reduce out-of-pocket expenses, eventually the entire social health insurance system should be further consolidated. ${ }^{26}$ Currently, there are two separate social health insurance schemes: URRBMI covering the urban non-employed and self employed population and rural population, and UEBMI covering the urban employed population and retired people. The out-of-pocket expenses for URRBMI are much higher and more likely to lead to catastrophic health expenses than the UEBMI. ${ }^{12}$ Consolidating the schemes and their risk pooling levels as well as equalising the benefit packages

Fig 1 | Level and share of out-of-pocket expenses in total health expenditures, 2003-17 through more government funding, would substantially reduce out-of-pocket expenses for urban non-employed and self employed people as well as rural populations. However, this increased government spending on healthcare will not be sustainable without further measures to increase health system efficiency, strengthen primary care, and control provider behaviour through reform of the payment systems.

\section{Catastrophic medical insurance and medical} aid should be expanded

Catastrophic health expenses disproportionately affect deprived populations. Table 2 shows that the incidence of catastrophic health expenses for the poorest fifth of the population was much higher than for the richest fifth. Household spending on health as a percentage of total household consumption expenditures also increased in both urban and rural areas, as shown in figure 2, but the increase in household expenditures on health seems to have been greater in rural than in urban areas (rural areas tend to be relatively underdeveloped).

Catastrophic medical insurance currently does not target poor people, and medical aid is relatively small in scale. Pilot studies using regional data have not shown that catastrophic medical insurance reduces the incidence of catastrophic health expenses. ${ }^{27}{ }^{28}$ Catastrophic medical insurance was designed to reduce the out-of-pocket burden for patients with critical illnesses but it currently covers all patients with critical illness, providing extra financial protection, as long as their out-of-pocket expenses are more than the average disposable income per capita in the local area. The cost sharing rate of catastrophic medical insurance (currently $50 \%$ ) is identical regardless of the patient's economic status, but poor people have a higher disease burden and need more financial protection. ${ }^{12}$ Not everyone eligible for catastrophic medical insurance will have catastrophic health expenses. To better protect vulnerable people, further increase in funding should be more focused on poor people, such as by linking benefit eligibility to household disposable income instead of an absolute threshold. The cost sharing rate could also be lower for poorer people. 


\begin{tabular}{|c|c|c|c|c|c|c|}
\hline \multirow{2}{*}{ Reference } & \multirow{2}{*}{ Year } & \multirow{2}{*}{ Region } & \multirow{2}{*}{ Population } & \multicolumn{3}{|c|}{$\%$ incurring catastrophic health expenses } \\
\hline & & & & Poorest & Average & Richest \\
\hline Meng et $\mathrm{al}^{14}$ & 2003 & National & All & N/A & 12.2 & N/A \\
\hline Meng et $\mathrm{al}^{14}$ & 2008 & National & All & N/A & 14 & N/A \\
\hline Meng et $\mathrm{al}^{14}$ & 2011 & National & All & N/A & 12.9 & N/A \\
\hline Xu et $\mathrm{al}^{21}$ & 2013 & Shaanxi Province & All & 22.4 & 15.8 & 12.9 \\
\hline Sun et $\mathrm{al}^{22}$ & 2014 & Inner Mongolia & Rural & N/A & 17.5 & N/A \\
\hline Wang $^{23}$ & 2014 & National & Rural & 31.6 & 15.8 & 5.7 \\
\hline $\mathrm{Xu}$ and $\mathrm{Chu}^{24}$ & 2015 & National & $\geq 45$ years old & N/A & 16.5 & N/A \\
\hline Jing et $\mathrm{al}^{25}$ & 2016 & Shandong Province & Type 2 diabetes & $17 .{ }^{1} \dagger$ & $13.8+$ & $9 .{ }^{3} \dagger$ \\
\hline
\end{tabular}

Medical aid in China covers only a minority of patients with catastrophic health expenses, although it aimed to cover everyone whose needs were not met by basic social health insurance schemes and catastrophic medical insurance. In 2011-16, medical aid covered around one quarter of the patients with catastrophic health expenses. It continued to impose benefit caps. Medical aid should be further expanded to cover all those who still incur catastrophic health expenses after catastrophic medical insurance reimbursements. It should also cap outof-pocket expenses for extremely poor people (ie, poverty alleviation household, Jian Dang $\mathrm{Li} \mathrm{Ka} \mathrm{Hu}$ ) as determined through strict eligibility criteria based on household disposable income, fixed assets, financial assets, real estate, etc.

\section{Conclusions}

By achieving near-universal population coverage of social insurance China has improved access to and use of health services and reduced the proportion of outof-pocket spending. Although the Chinese government attempted to provide additional financial protection, catastrophic health expenses for poor people are still high. This group should be targeted within the current insurance system to enhance

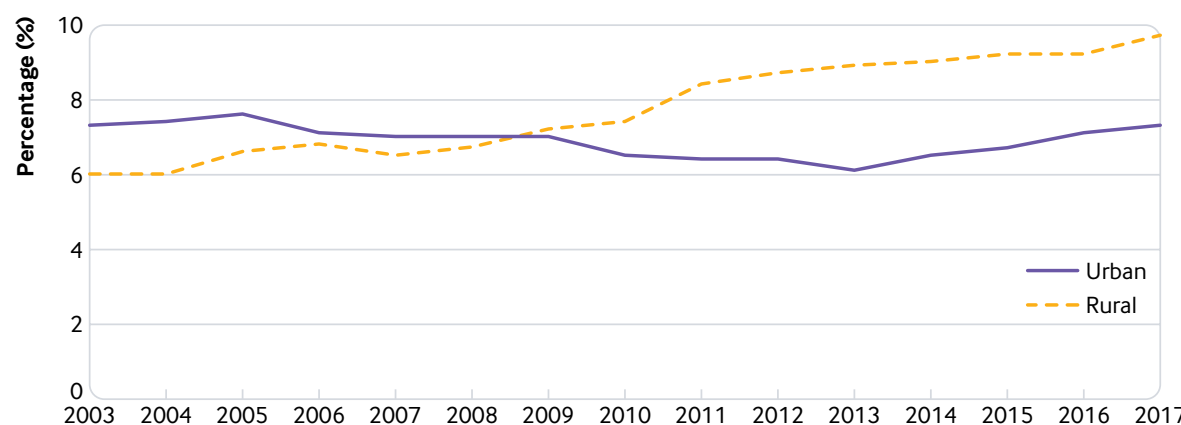

expenditures, 2003-17 financial protection in China. Such targeting requires a clear and integrated policy encompassing the basic social health insurance schemes, catastrophic medical insurance, medical aid, and improved healthcare efficiency. Protection of poor people from healthcare costs in health poverty alleviation (Jian Kuang Fu Pin) should be regarded as an important element of targeted poverty alleviation (Jing Zhun Fu $P i n)$ in China, to break the vicious cycle of illness induced poverty (Yin Bing Zhi Pin) and return to poverty because of illness (Yin Bing Fan Pin).

We thank Dr Ke Xu from WHO for helpful comments on our manuscript.

Competing interests: We have read and understood BMJ policy on declaration of interests and have no relevant interests to declare.

Provenance and peer review: Commissioned; externally peer reviewed.

This article is part of series proposed by the Peking University China Center for Health Development Studies and commissioned by The BMJ. The BMJ retained full editorial control over external peer review, editing, and publication of these articles. Open access fees are funded by the Peking University Health Science Center.

Hai Fang, professor $^{1}$

Karen Eggleston, senior fellow ${ }^{2,3}$

Kara Hanson, professor ${ }^{4}$

Ming Wu, professor ${ }^{5}$

${ }^{1}$ China Center for Health Development Studies, Peking University, Beijing, China
${ }^{2}$ Shorenstein Asia Pacific Research Center, Freeman Spogli Institute for International Studies, Stanford University, Stanford, California, USA

${ }^{3}$ National Bureau of Economic Research, USA

${ }^{4}$ Faculty of Public Health and Policy, London School of

Hygiene and Tropical Medicine, London, UK

${ }^{5}$ Department of Health Policy and Management,

School of Public Health, Peking University, Beijing, China

Correspondence to: Hai Fang

hfang@hsc.pku.edu.cn

\section{(c) (1) (8)}

\section{This is an Open Access article distributed in} accordance with the Creative Commons Attribution Non Commercial (CC BY-NC 4.0) license, which permits others to distribute, remix, adapt, build upon this work non-commercially, and license their derivative works on different terms, provided the original work is properly cited and the use is non-commercial. See: http://creativecommons.org/ licenses/by-nc/4.0/.

\section{Check for updates}

1 Chan M, Brundtland G. Universal health coverage: an affordable goal for all. World Health Organization, 2016. https://www.who.int/mediacentre/ commentaries/2016/universal-health-coverage/en/

2 World Health Organization. Universal coveragethree dimensions. https://www.who.int/health_ financing/strategy/dimensions/en/

3 United Nations. Sustainable development goals 3: ensure healthy lives and promote well-being for al at all ages. 2016. https://sustainabledevelopment. un.org/sdg $\underline{3}$

4 World Health Organization, World Bank. Tracking universal health coverage: 2017 global monitoring report. https://www.who.int/healthinfo/universal_ health_coverage/report/2017/en/

5 Meng $\mathrm{Q}$, Mills A, Wang L, et al. What can we learn from China's health system reform? BMJ 2019;365:12349. doi:10.1136/bmj.12349

6 National Health Commission. China health statistical yearbook. China Union Medical University Press, 2018.

7 Central Committee of the Communist Party of China and the State Council. Opinions on deepening health system reform. 2009.

8 Pan XF, Xu J, Meng Q. Integrating social health insurance systems in China. Lancet 2016;387:12745. doi:10.1016/S0140-6736(16)30021-6

9 Chinese Ministry of Finance and Ministry of Civil Affairs. [Announcement about Management Methods of Urban Rural Medical Aid Funding. December 23, 2013]. http://fgk.mof.gov.cn/law/ getOneLawlnfoAction.do?law_id=7402으

10 Ministry of Health. China health statistical yearbook. China Union Medical University Press, 2004

11 Liang L, Langenbrunner JC. The long march to universal coverage: lessons from China. Universal Health Coverage Studies Series (UNICO) No 9. World Bank, 2013.

12 Center for Health Statistics and Information, National Health and Family Planning Commission. An analysis report of national health services survey in China, 2013. China Union Medical University Press, 2015.

13 Center for Health Statistics and Information, Ministry of Health. [Statistical Communiqué of China Health Development Status 2003]. http://www.nhfpc.gov. cn/zwgkzt/pgb/200805/34849.shtm!

14 Meng Q, Xu L, Zhang Y, et al. Trends in access to health services and financial protection in China between 2003 and 2011: a cross-sectional study. Lancet 2012;379:805-14. doi:10.1016/S01406736(12)60278-5 
15 Moses MW, Pedroza P, Baral R, et al. Funding and services needed to achieve universal health coverage: applications of global, regional, and national estimates of utilisation of outpatient visits and inpatient admissions from 1990 to 2016 , and unit costs from 1995 to 2016. Lancet Public Health 2019;4:e49-73. doi:10.1016/S24682667(18)30213-5

16 Fu W, Zhao S, Zhang Y, Chai P. Goss J. Research in health policy making in China: out-ofpocket payments in Healthy China 2030 BMJ 2018;360:k234. doi:10.1136/bmj.k234

17 Li H, Jiang L. Catastrophic medical insurance in China. Lancet 2017;390:1724-5. doi:10.1016/S01406736(17)32603-X

18 Ministry of Human Resource and Social Security [Significant effectiveness of urban-rural resident catastrophic medical insurance]. 2017. http://www.gov.cn/xinwen/2017-10/28/ content 5235083.htm

19 Xie B, Huo M, Wang Z, et al. Impact of the new cooperative medical scheme on the trend of catastrophic health expenditure in Chinese rural households: results from nationally representative surveys from 2003 to 2013. BMJ Open 2018;8:e019442. . doi:10.1136/ bmjopen-2017-019442

20 Xu K. Distribution of health payments and catastrophic expenditures, methodology. Discussion paper 2. WHO, 2005.

21 Xu Y, Gao J, Zhou Z, et al. Measurement and explanation of socioeconomic inequality in catastrophic health care expenditure: evidence from the rural areas of Shaanxi Province. BMC Health Serv Res 2015;15:256. doi:10.1186/s12913-0150892-2

22 Sun J, Liabsuetrakul T, Fan Y, McNeil E. Protecting patients with cardiovascular diseases from catastrophic health expenditure and impoverishment by health finance reform. Trop Med Int Health 2015;20:1846-54. doi:10.1111/tmi.12611

23 Wang Q. [Effects of catastrophic medical expenditure on rural poverty in China]. [Chinese.] Chinese Journal of Health Policy 2016;9(2):6-10.

$24 \mathrm{Xu} \mathrm{W}$, Chu F. [Study on catastrophic health expenditure level and influencing factors-An analysis based on CHARLS data].[Chinese.]Social Secur Stud 2018;5:64-72.

25 Jing Z, Chu J, Imam Syeda Z, et al. Catastrophic health expenditure among type 2 diabetes mellitus patients: A province-wide study in Shandong, China. J Diabetes Investig 2019;10:283-9. doi:10.1111/jdi.12901.

26 Meng Q, Fang H, Liu X, Yuan B, Xu J. Consolidating the social health insurance schemes in China: towards an equitable and efficient health system. Lancet 2015;386:1484-92. doi:10.1016/S01406736(15)00342-6

27 Gao G, Ma C, Hu X, Yang X, Duan T, Jia J. [Evaluation on the effect of the catastrophic medical expenditure insurance for rural residents on alleviating catastrophic health expenditure]. [Chinese.] Social Secur Stud 2017;2:69-76.

28 Fang P, Pan Z, Zhang X, Bai X, Gong Y, Yin X. The effect of critical illness insurance in China. Medicine (Baltimore) 2018;97:e11362. doi:10.1097/ MD.0000000000011362

Cite this as: BMJ 2019;365:12378

http://dx.doi.org/10.1136/bmj.l2378 